\title{
Association between Brainerd Diarrhea and Zebra Mussel Infestations
}

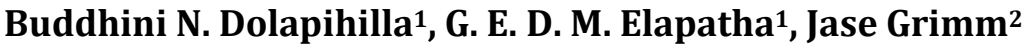 \\ ${ }^{1}$ Faculty of Medicine, University of Colombo, Colombo, Sri Lanka \\ ${ }^{2}$ University of the People, California, USA \\ Email: buddhinin1919@gmail.com
}

How to cite this paper: Dolapihilla, B.N. Elapatha, G.E.D.M. and Grimm, J. (2021) Association between Brainerd Diarrhea and Zebra Mussel Infestations. Journal of Biosciences and Medicines, 9, 14-22. https://doi.org/10.4236/jbm.2021.910002

Received: August 30, 2021

Accepted: October 5, 2021

Published: October 8, 2021

Copyright (c) 2021 by author(s) and Scientific Research Publishing Inc. This work is licensed under the Creative Commons Attribution International License (CC BY 4.0).

http://creativecommons.org/licenses/by/4.0/

(c) (i) Open Access

\begin{abstract}
Brainerd Diarrhea is a syndrome of acute onset of watery, non-bloody diarrhea that lasts for a duration of 4 weeks or more. The index case of Brainerd Diarrhea was recorded in 1983, in the first such outbreak in Brainerd, Minnesota. In 1989, a prohibited invasive species named Zebra Mussels (Dreissena polymorpha) were found in the great lakes of the United States. The 7 recorded outbreaks of Brainerd diarrhea were correlated with the location and time of zebra mussel infestations. The first outbreak that occurred due to consumption of raw milk took place in Minnesota which is near the waters infested by zebra mussels. All other outbreaks were related to consumption of contaminated unchlorinated water occurred in regions not directly close to the infested rivers. However, since infestations are thought to occur due to human activity, undocumented infestations faraway are still possible. Evidence shows minor correlations between Brainerd Diarrhea outbreaks and Zebra Mussel infestations. However, none of the facts are strong enough to establish or deny a significant correlation or causation. Further cohort studies and research need to be done on the recent discoveries of Zebra Mussel infestations and new Brainerd diarrhea outbreaks. The primary search engine used to gather information for this review was ScienceDirect and PubMed. More than 35 articles and case reports were reviewed and only 20 were shortlisted and used as references. None of the studies included were restricted to study design, but studies with less than 10 participants/patients were excluded from the review.
\end{abstract}

\section{Keywords}

Brainerd Diarrhea, Zebra Mussel Infestation, Campylobacter, Mycobacterium

\section{Introduction}

Brainerd Diarrhea is defined as an acute onset of watery diarrhea that lasts for a 
duration of 4 weeks or more. The name is derived from the town Brainerd in Minnesota where the first outbreak of this diarrhea was reported in 1983 [1]. Patients with Brainerd Diarrhea typically experience 10 - 20 episodes of explosive diarrhea [2]. Some of the associated symptoms include fecal incontinence, abdominal cramps and lethargy [1] [2]. Constitutional symptoms are rare with this type of diarrhea [2]. A total of 7 major outbreaks of Brainerd Diarrhea have been recorded since 1983 [3] [4] [5] [6] [7]. One outbreak was recorded in an American cruise ship and the rest were in different parts of the USA [1].

The major route of transmission of Brainerd Disease in the first outbreak was consumption of raw milk. All of the patients had consumed the milk approximately 3 weeks earlier [8]. However, for the rest of the 6 outbreaks, the vector agent was reported as contaminated, unchlorinated or unboiled water [1]. To date, no man-to-man transmission of this Diarrhea has been recorded [1].

A few years later, in June 1988 a prohibited invasive species named Zebra Mussels (Dreissena polymorpha) was discovered in the Lake St. Clair of the Great Lakes in Minnesota. Although the true pathway of introduction of these species to American waters remains unknown, experts believe that it's originated as stowaways from European ships from their freshwater ports [9]. Natural methods of dispersal of zebra mussels in water include swimming, water currents and attachment to other marine organisms. However, marine biologists suggest that the major activities that result in inter-river transport and infestation of mainland freshwater surfaces include human influenced vectors such as shipping, sailing, fish stocking operations, collection of engine cooling water and dredging [9].

Since the emergence of Brainerd Diarrhea occurred not so long before the first reported finding of zebra mussels in the Great River and most cases of diarrhea had spread from consumption of unclean water, it could be hypothesized that there is a correlation between these two variables.

\section{Timeline, Geographical and Transmission Based Correlations between Brainerd Diarrhea Outbreaks and Zebra Mussel Infestations}

The first outbreak of Brainerd Diarrhea was recorded in Minnesota in 1983. This was the largest outbreak recorded in history with 122 casualties [1]. All cases in this particular outbreak had consumed raw milk 3-weeks prior to showing signs of diarrhea [8]. Although there were no further investigations done on the dairy where the raw milk was produced, it could have been because of a contamination from water. Nevertheless, since the source of water for the dairy farm is unknown, it is not possible to correlate the source of this infection to zebra mussels or any specific water bodies. However, it should be noted that based on the size of the zebra mussels first found in the Great River in 1989, experts claimed that the mussels could have been possibly introduced into the water in 1986 [9]. This is only 3 years after the first outbreak of Brainerd diarrhea. It should also be highlighted (as indicated in Table 1) that the river where the first 
Table 1. Brainerd diarrhea outbreaks and zebra mussel infestations recorded in history. Table shows the location and year of the outbreaks and infestation.

\begin{tabular}{lcrlll}
\hline \multicolumn{2}{l}{ Brainerd Diarrhea outbreak in US } & \multicolumn{2}{l}{ Zebra Mussel Expansion in US } & Date \\
\hline \multicolumn{1}{l}{ Location } & Date & & Location & 1989 \\
\hline 1 & Minnesota & 1983 & 1 & Great Lakes Basin, Minnesota & 1990 \\
2 & Texas & 1985 & 2 & Western Lake Erie, Ontario and Detroit River & Late 1989 \\
3 & Illinois & 1987 & 3 & Entire Great Lake Basin and Lake Ontario & 1990 \\
4 & Galapagos Island & 1992 & 4 & $\begin{array}{l}\text { Mohawk River and Hudson River, New York } \\
\text { City }\end{array}$ & 1992 \\
5 & Texas & 1996 & 5 & $\begin{array}{l}\text { Illinois, Mississippi, Southern Minnesota, } \\
\text { Ohio, Kentucky Tennessee and Arkansas }\end{array}$ & Late 1992 \\
6 & California & 1998 & 6 & Vermont and Georgia & 1993 \\
\hline
\end{tabular}

infestation of zebra mussels was reported is found in the state of Minnesota, the location of first Brainerd Diarrhea outbreak.

In 1985 another outbreak of Brainerd Diarrhea was reported in San Antonio, Texas [7]. 10 patients identified in this outbreak denied having used raw milk in their diet. Furthermore, the only coinciding food source for all the patients was a Mexican restaurant that also claimed not to use any dairy products like cheese or milk in their dishes. This shows that Brainerd Diarrhea could be transmitted from food sources other than raw milk. Nevertheless, no further investigations were carried out on the raw materials supplier of the Mexican restaurant. Therefore, any relation to zebra mussels cannot be established. Additionally, Texas is considerably far from the initial site of zebra mussel infestation by 1985 [7].

The third outbreak of Brainerd Diarrhea seen in Rural Henderson included 72 patients with chronic diarrhea in between May and August of 1987 [5]. A study was conducted with a sample frame of individuals showing symptoms and non-symptomatic close contacts. The only significant finding for the vector in this outbreak was untreated well water in a local restaurant. The water was taken from a drilled well nearby the restaurant. Routine testing of the water from this well was carried out between 1981 and 1987, and it showed normal levels of coliforms. In 1987, after 2 mild earthquakes and 3 power outages near the well, the water was tested again. The coliform levels were found to be higher this time and the well was later chlorinated. It is possible that this rise in coliform levels caused the outbreak. However, no bacterial, mycobacterial, viral or parasitic agents that are entheogenic were discovered in the stool sample or the well water used in the restaurant [5]. There were isolated cases of Diarrhea due to Giardia lamblia in 1 case patient and Blastocystis hominis in 2 others. Few months after the chlorination of water, a test done on the well water showed very high levels of fecal coliforms, but this was claimed to be attributed due to the poor infrastructure of the well. Several other nearby wells showed normal levels of coliforms. Approximately 5 years later, in late 1992, zebra mussels were found from the Illinois 
river and the Mississippi River [9]. Illinois lies in close proximity to the eastern bank of the Mississippi River. Contamination of land surface waters due to the zebra mussel infestation is possible although not supported by any literature. In addition, considering that other wells nearby had normal coliform counts, a mass contamination from the river is unlikely. However, a comparison based on the infrastructural integrity of all the wells was not established.

The only outbreak outside America took place in a local cruise ship returning from Galapagos Island, Ecuador in 1992 [3]. Among all travelers who participated in a study, 207 [52\%] of them reported diarrhea as a symptom. Only 54 travelers in the cruise reported chronic diarrhea that fits into the Brainerd Diarrhea definition. Possible vectors that had a significant association with all case patients were unbottled water, shore trips and ice served in drinks. The milk that was served in the ship was pasteurized and did not have significant association with patients as well. There was no causative agent identified in the microbiological investigations. Incidental findings of Entamoeba coli [2], Blastocystis hominis [2], Candida albicans [3], Candida lambica [1] and Campylobacter [1] were seen. The cause for this outbreak was considered as consumption of unclean water as the storage tanks in the ship showed no signs of free chlorine. In addition, the cases were seen after repairs were done to the ship's plumbing system. The route of the ship did not include any sea area infested by zebra mussels [9]. And since the source of water in the tank storage of the ship is unknown, it is not possible to correlate this outbreak with zebra mussels.

Next documented Brainerd Diarrhea Outbreaks were ones that occurred in two restaurants based in Texas and California in 1996 and 1998 respectively. The outbreak in California included 23 patients who had a significant association with ice consumption from a restaurant. The restaurant used chlorinated tap water and no pipe repairs were done as well [10]. The other outbreak that took place in Red River Valley of Texas included 114 patients showing symptoms of Brainerd Diarrhea. This outbreak was associated with consumption of tap water and salad bar tomatoes. The restaurant had plumbing, and sanitation and the investigations done on the tap water revealed multiple marine organisms such as rotifers and algae [4]. Both outbreaks reported very rare cases of campylobacter species in the stool of patients. Like all other previous incidents, they were unable to identify a causative agent. It should be noted that California and Texas are considerably far from the sites of zebra mussel infestations. However, as mentioned before, since the major carriers of this species are suspected to be humans, it cannot be ruled out that human activity would not have introduced zebra mussels to nearby water bodies by 1998 .

In a lot of Brainerd Diarrhea outbreaks, it has been established that drinking boiled water prevents contraction of the disease [3] [4] [10]. This does support the idea that it is caused by some sort of micro-organism. In addition, many case studies on the outbreaks of Brainerd Diarrhea assess the treatment outcome after the use of antibiotics. None of the patients had any relief from different courses 
of post-antibiotic treatment [3] [4] [5] [7] [10]. This could mean that either the causative agent is not bacterial, or the causative species of bacteria is resistant to a large spectrum of antibiotics. A lot of outbreaks also had few incidents of other pathogens among which campylobacter species was the most common. However, it should be noted that symptoms in these patients also did not subside after the normal treatment regime for campylobacter species, which suggests presence of another causative agent [5] [10].

Since the review is based on correlating outbreaks aforementioned to zebra mussel infestations, it is vital to highlight the changes that occur in a water body due to introduction of these species. Zebra Mussels (Figure 1) feed on phytoplankton found in the water and enhance water clarity [11]. This may sound beneficial; however, the consequences of this phenomenon are in fact detrimental. A study published in Association for the Sciences of Limnology and Oceanography has recorded that the percentage abundance of Microcystis aeruginosa (a type of phytoplankton) has increased dramatically after the introduction of zebra mussels to the Gull River [12]. Microcystis aeruginosa is a key organism in the bloom of cyanobacteria in waters and often considered hepatotoxic [13]. One of the most harmful toxins released from this cyanobacterium is Microcystin [13]. Transmission of microcystin or otherwise known as Cyanobacterial

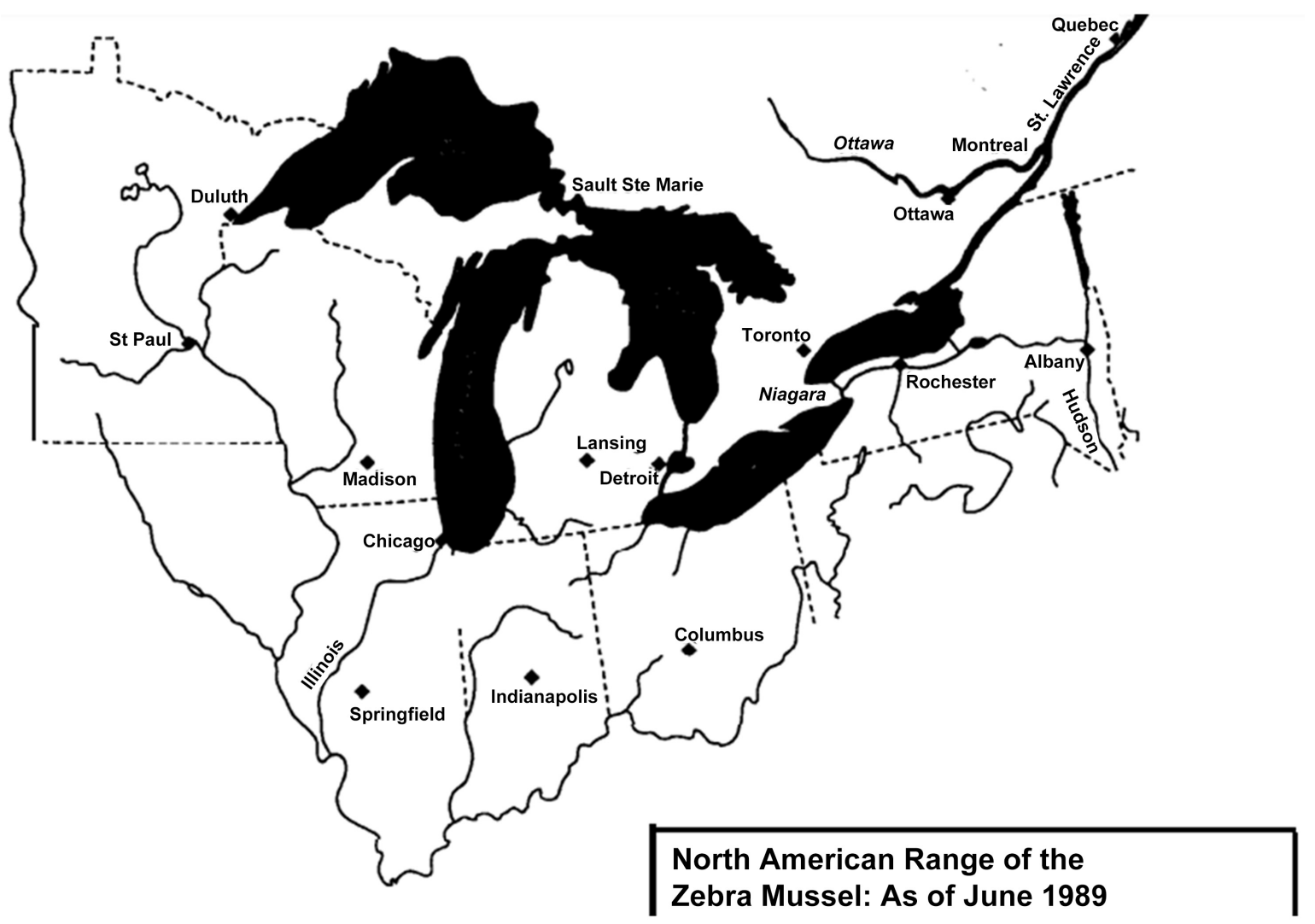

Figure 1. Geographical distribution of zebra mussel. Region highlighted in black shows areas infested by zebra mussels as of June 1989. Red cross indicates the location of the first Brainerd Diarrhea outbreak. Adapted from Map compiled by New York Sea Grant. 
Harmful Algal Bloom (cHAB) is known to cause symptoms such as nausea, vomiting and diarrhea but is not similar to that of Brainerd Diarrhea [14]. Moreover, a study published in 2019 that assessed the concentration and resistance of bacterial species in zebra mussels indicated that the soft tissues of mussels had 132 times more bacterial indicators that in water [15]. The enterococci ranged from $4-59 \mathrm{cfu} \cdot \mathrm{ml}^{-1}$ in the water and $240-1450 \mathrm{cfu} \cdot \mathrm{ml}^{-1}$ in zebra mussels. Most abundant were E. coli species. Additionally, 33\% of the bacteria found in zebra mussels were resistant to multiple antibiotics [15]. This enhances the chances of mussel-eating fish and waterflow to spread illnesses [11]. Regardless, since no causative agent was found in any of the outbreaks it is not possible to conclude that zebra mussels could have a role in the spread of Brainerd Diarrhea.

\section{Hypotheses on a Causative Agent}

Diarrhea is one of the commonest reasons why adults seek medical treatment [16]. However, any prolonged case of diarrheal illness without an obvious etiologic finding used to be considered as irritable bowel syndrome. It is possible for there to be outbreaks of Brainerd Diarrhea before but wasn't recognized as a separate entity. It wasn't until 1983, when many patients sought treatment for chronic diarrhea in Brainerd, a common source of infection was considered [16]. The special feature of this outbreak was that all patients consumed raw milk 3 weeks before the appearance of diarrheal symptoms [16]. Hence the name, "Brainerd Diarrhea", came into use. However, scientists have not been able to find a definitive causative agent to this unique disease.

The identification of causative agent is very important because it will enhance our understanding of the disease and that will allow us to develop the specific treatment plans. More importantly, it will help us in detecting the disease earlier and hopefully prevent the future outbreaks.

Several other outbreaks of Brainerd Diarrhea have since occurred [3] [4] [5] [6] [7]. However, the outbreaks that followed linked diarrheal cases not only to milk, but to uncleaned water as well. Interestingly, pasteurized milk or boiled water is not linked with the disease [5] [6] [9] [10] [11], which gives us reasons to believe that there is a pathogen involved which is deactivated at high temperatures. In addition, the epidemiologic and clinical findings are remarkably similar, strongly suggesting a common etiologic process [6]. Based on the symptoms, characteristics and microbiological findings of the cases studied so far, there are a few hypotheses that we can make regarding its etiologic agent.

The first of such hypotheses is that Brainerd Diarrhea is caused by a microorganism unknown to man. This hypothesis can be supported since the clinical features of Brainerd Diarrhea are unique, and patients failed to respond to any antibiotic treatment [16]. This should not be a surprising hypothesis as new microbial pathogens continue to be discovered. For instance, the emergence of Legionella species (causative agent of Legionnaire's disease) in late $20^{\text {th }}$ century should be ample proof that this is entirely possible [17]. 
The second hypothesis we could make is that Brainerd Diarrhea could be related to Morgellons Disease (MD), which like Brainerd Diarrhea, experts failed to find a conclusive causative agent [18]. It used to be considered as a delusional disorder, until researchers found strong association between $\mathrm{MD}$ and spirochetal infection, the same organism causing Lyme disease [18]. Lyme Diseases are known to cause gastrointestinal symptoms such as abdominal discomfort, gas, and fatigue [19]. These same symptoms are seen in Brainerd Diarrhea as well, suggesting a link between these two diseases. This hypothesis is further supported as the largest population of Morgellons Disease are found in California and Texas [20], just like Brainerd Diarrhea.

The third hypothesis we can make is that Brainerd Diarrhea is associated with a Mycobacterium species. For example, Mycobacterium marinum is a slow-growing bacteria and it is usually found in fresh and saltwater [21]. Just like Brainerd diarrhea, patients infected with $M$. marinum presents symptoms after 3 weeks of exposure to non-chlorinated water [21].

\section{Conclusions}

Brainerd Diarrhea is a unique disease, and it is completely different from typical chronic diarrhea. As mentioned before, most cases of Brainerd Diarrhea were associated with unchlorinated water consumption, and we hypothesized that this could be due to zebra mussel infestation of the great lakes of USA. Arguments which support the hypothesis include finding the first evidence of zebra mussels approximately 3 years after the first case of Brainerd diarrhea and the fact that this happened in the same state of Minnesota. However, in the outbreak that followed (Texas 1985), we could not find any correlation to zebra mussel infestation. But this was mainly due to lack of investigation to find the supplier of raw materials of the Mexican restaurant in which all patients dined in before showing the symptoms. Similarly, we could not correlate the outbreaks in 1987 and 1992 to zebra mussels either due to various limitations in the study. After studying the last 2 outbreaks (Texas 1996 and California 1998), we found that zebra mussels could have been introduced to the water bodies of these two states by human activities, though not confirmed by any investigation.

In summary, it is not possible to confirm or rule out the association between zebra mussels and Brainerd diarrhea based on current literature. Although we established various hypotheses regarding its etiological agent, it cannot be confirmed either without further investigation. Hence, further research on Brainerd Diarrhea needs to be conducted to assess the causative agent and its relations. More recent cross-sectional studies are required to establish such factors as information from previous outbreaks are considerably limited.

\section{Conflicts of Interest}

The authors declare no conflicts of interest regarding the publication of this paper. 


\section{References}

[1] Centers for Disease Control and Prevention (2021) Brainerd Diarrhea. https://www.cdc.gov/ncezid/dfwed/diseases/brainerd-diarrhea/index.html

[2] Davis, C.P. (2021) Medical Definition of Brainerd Diarrhea. MedicineNet. https://www.medicinenet.com/brainerd_diarrhea/definition.htm

[3] Mintz, E.D., Todd Weber, J., Guris, D., Puhr, N., Wells, J.G., Yashuk, J.C., et al. (1998) An Outbreak of Brainerd Diarrhea among Travelers to the Galapagos Islands. Journal of Infectious Diseases, 177, 1041-1045. https://doi.org/10.1086/515237

[4] Kimura, A.C., Mead, P., Walsh, B., Alfano, E., Gray, S.K., Durso, L., et al. (2006) A Large Outbreak of Brainerd Diarrhea Associated with a Restaurant in the Red River Valley, Texas. Clinical Infectious Diseases, 43, 55-61. https://doi.org/10.1086/504805

[5] Parsonnet, J., Trock, S.C., Bopp, C.A., Wood, C.J., Addiss, D.G., Alai, F., et al. (1989) Chronic Diarrhea Associated with Drinking Untreated Water. Annals of Internal Medicine, 110, 985-991. https://doi.org/10.7326/0003-4819-110-12-985

[6] Mintz, E.D., Parsonnet, J. and Osterholm, M.T. (1993) Chronic Idiopathic Diarrhea. The New England Journal of Medicine, 328, 1713-1714. https://doi.org/10.1056/NEJM199306103282314

[7] Martin, D.L. and Hoberman, L.J. (1986) A Point Source Outbreak of Chronic Diarrhea in Texas: No Known Exposure to Raw Milk. JAMA, 256, Article No. 469.

[8] Centers for Disease Control and Prevention (1984) Epidemiologic Notes and Reports Chronic Diarrhea Associated with Raw Milk Consumption-Minnesota. Morbidity and Mortality Weekly Report, 33, 521-522, 527-528. https://www.cdc.gov/mmwr/preview/mmwrhtml/00000406.htm

[9] O’Neill Jr., C.R. and Dextrase, A. (1994) The Introduction and Spread of the Zebra Mussel in North America. 4th International Zebra Mussel Conference, Wisconsin, 7-10 March 1994, 433-446.

[10] Vugia, D.J., Abbott, S., Mintz, E.D., Richmond, J., Meshulam, S., Stokes, K., et al. (2006) A Restaurant-Associated Outbreak of Brainerd Diarrhea in California. Clinical Infectious Diseases, 43, 62-64. https://doi.org/10.1086/504808

[11] Invasive Mussel Collaborative (n.d.) What Are Invasive Mussels? https://invasivemusselcollaborative.net/about/mussel-facts/.

[12] Sarnelle, O., Wilson, A.E., Hamilton, S.K., Knoll, L.B. and Raikow, D.F. (2005) Complex Interactions between the Zebra Mussel, Dreissena polymorpha, and the Harmful Phytoplankter, Microcystis aeruginosa. Limnology and Oceanography, 50, 896-904. https://doi.org/10.4319/lo.2005.50.3.0896

[13] Qu, J., Shen, L., Zhao, M., Li, W., Jia, C., Zhu, H., et al. (2018) Determination of the Role of Microcystis aeruginosa in Toxin Generation Based on Phosphoproteomic Profiles. Toxins, 10, Article No. 304. https://doi.org/10.3390/toxins10070304

[14] Centers for Disease Control and Prevention (2018) Facts about Cyanobacterial Harmful Algal Blooms for Poison Center Professionals. Centers for Disease Control and Prevention, Atlanta.

https://www.cdc.gov/habs/materials/factsheet-cyanobacterial-habs.html

[15] Bighiu, M.A., Norman Haldén, A., Goedkoop, W. and Ottoson, J. (2019) Assessing Microbial Contamination and Antibiotic Resistant Bacteria Using Zebra Mussels (Dreissena polymorpha). Science of the Total Environment, 650, 2141-2149. https://doi.org/10.1016/j.scitotenv.2018.09.314

[16] Blaser, M.J. (1986) Brainerd Diarrhea: A Newly Recognized Raw Milk-Associated 
Enteropathy. Journal of the American Medical Association, 256, 510-511.

https://jamanetwork.com/journals/jama/article-abstract/361461 https://doi.org/10.1001/jama.1986.03380040084034

[17] Cakilci, B. and Gunduz, M. (2015) Legionella: A Fascinating Bacterium Uncovered in the Twentieth Century. Clinical Microbiology News Letter, 37, 119-123.

https://doi.org/10.1016/j.clinmicnews.2015.07.003

[18] Middelveen, M.J., Fesler, M.C. and Stricker, R.B. (2018) History of Morgellons Disease: From Delusion to Definition. Clinical, Cosmetic and Investigational Dermatology, 11, 71-90. https://doi.org/10.2147/CCID.S152343

[19] Maderis, T. (2021) Gastrointestinal Symptoms of Lyme Disease. https://drtoddmaderis.com/gastrointestinal-lyme-disease

[20] Stricker, R. (2010) Morgellons Disease: Analysis of a Population with Clinically Confirmed Microscopic Subcutaneous Fibers of Unknown Etiology. Clinical, Cosmetic and Investigational Dermatology, 2010, 67-68.

https://doi.org/10.2147/CCID.S9520

[21] Stoppler, M.C. (2020) Mycobacterium marinum. MedicineNet. https://www.medicinenet.com/mycobacterium_marinum/article.htm 